\title{
Expression profiles of heat shock protein 27 and $\alpha B$-crystallin and their effects on heat-stressed rat myocardial cells in vitro and in vivo
}

\author{
SHU TANG ${ }^{1}$, HONGBO CHEN $^{1}$, YANFEN CHENG ${ }^{1}$, MOHAMMAD ABDEL NASIR $^{1}$, \\ NICOLE KEMPER $^{2}$ and ENDONG BAO ${ }^{1}$
}

\author{
${ }^{1}$ College of Veterinary Medicine, Nanjing Agricultural University, Nanjing, Jiangsu 210095, P.R. China; \\ ${ }^{2}$ Institute for Animal Hygiene, Animal Welfare and Farm Animal Behaviour, \\ University of Veterinary Medicine Hannover, Foundation, Hannover D-30173, Germany
}

Received October 9, 2014; Accepted June 26, 2015

DOI: $10.3892 / \mathrm{mmr} .2015 .4693$

\begin{abstract}
The present study established a heat-stressed rat heart model, and used an $\mathrm{H} 9 \mathrm{c} 2$ myocardial cell line to investigate the expression profiles of heat shock protein (Hsp) 27 and $\alpha \mathrm{B}$-crystallin, both in vivo and in vitro. Rats and myocardial cells were subjected to $42^{\circ} \mathrm{C}$ for $0,20,40$, 60,80 or $100 \mathrm{~min}$, following which the $\mathrm{mRNA}$ and protein expression levels of Hsp27 and $\alpha \mathrm{B}$-crystallin were measured. Following heat shock, the protein expression levels of Hsp27 and $\alpha \mathrm{B}$-crystallin were significantly decreased in the rat heart cells in vivo, whereas their mRNA levels were significantly increased. The opposing association between the protein and mRNA expression levels of Hsp27 and $\alpha \mathrm{B}$-crystallin suggests that the progression from mRNA into proteins via translation may delayed, or proteins may exist as either oligomers or in the phosphorylated form under heat stress. In vitro, Hsp27 and $\alpha \mathrm{B}$-crystallin exhibited similar reductions in the protein levels at 40 and $60 \mathrm{~min}$, then increased to normal values following $80 \mathrm{~min}$ of heat stress. However, the mRNA levels were not consistent with the protein levels. The mRNA levels of Hsp27 and $\alpha \mathrm{B}$-crystallin did however exhibit similar tendencies following $60 \mathrm{~min}$ of heat stress. The present study investigated these apparently conflicting results between the in vitro cell line and the in vivo body system. The results demonstrated that the protein and mRNA expression levels of Hsp27 and $\alpha \mathrm{B}$-crystallin exhibited similar trends in vivo and in vitro, respectively. These results were confirmed by analysis with STRING 9.1 software, which indicated that Hsp27 and $\alpha \mathrm{B}$-crystallin are co-expressed in rat myocardial cells.
\end{abstract}

Correspondence to: Professor Endong Bao, College of Veterinary Medicine, Nanjing Agricultural University, 1 Weigang Road, Nanjing, Jiangsu 210095, P.R. China

E-mail: b_endong@njau.edu.cn

Key words: $\alpha \mathrm{B}$-crystallin, heat shock protein 27 , myocardial cells, heat stress, in vivo, in vitro
However, the individal cell lines and whole body system exhibited different trends in Hsp27 and $\alpha \mathrm{B}$-crystallin levels prior to and following heat stress, thus require further investigation.

\section{Introduction}

High environmental temperatures may be fatal and are associated with sudden death in animals and humans (1). The incidence of heat-associated mortality is likely to increase with global warming, and with the predicted increase in frequency and intensity of heat waves $(2,3)$. Scientific reports have indicated that hyperthermia $\left(40-45^{\circ} \mathrm{C}\right)$ is cytotoxic $(2,4)$ and prolonged exposure to temperatures $>42^{\circ} \mathrm{C}$ causes cellular damage, and protein denaturation and aggregation (5). However, the causes of the progression from heat stress to lethal heat stroke and clinical hyperthermia, and the mechanisms underlying hyperthermia-induced cytotoxicity, remain poorly understood $(6,7)$. A previous study demonstrated that heart attacks caused by high temperatures are associated with high mortality due to heart diseases such as hypertension, coronary vessel occlusion, and atherosclerosis (8).

Heat stress induces the expression of heat-shock proteins (Hsps) $(9,10)$. Hsps are usually divided into small Hsps (sHsps) (molecular mass, <40 kDa), and Hsp40, Hsp60, Hsp70 (68-80 kDa), Hsp90 (83-99 kDa), and Hsp100 protein families. All Hsp families share a common chaperoning function. It is generally accepted that Hsps prevent cells from lethal thermal damage (11). A lack of Hsp synthesis is associated with exponential cell death (12). Furthermore, a previous study reported that stretched and decreased myocyte shortening results in an increase in the expression levels of Hsps in the isolated perfused rabbit heart (13).

sHsps are ubiquitous components of protein quality control cell networks, and can be induced by numerous events including hypoxia, heat shock, ultraviolet light, and toxic free radicals $(9,14)$. As with other chaperones, sHsps have a high capacity to bind unfolded proteins and facilitate substrate refolding (15). Hsp27 and $\alpha \mathrm{B}$-crystallin belong to the $\mathrm{sHsp}$ superfamily, and are functional, stress-induced sHsps that are expressed in numerous tissues types, notably in muscles (7). In 
humans, there are 10 genes that encode sHsps (16); however, only Hsp27 and $\alpha \mathrm{B}$-crystallin function as molecular chaperones $(17,18)$. The rapid upregulation of sHsps is regulated by transcriptional and translational mechanisms (19). Hsp27 and $\alpha \mathrm{B}$-crystallin possess a homologous $\alpha$-crystallin domain, which prevents actin microfilament disruption under stress conditions (7). The effects of sHsps on the cytoskeleton may be important not only in individual cell tolerance to stress through cytoskeletal stabilization, but may also be integral to the protection of the whole organism through the maintenance of endothelial and epithelial barrier functions (20).

Presently, it remains uncertain whether Hsp27 and $\alpha \mathrm{B}$-crystallin proteins and genes induce similar changes in heart cells and tissues in response to heat stress in vitro and in vivo. Therefore, the present study investigated the expression levels of Hsp27 and $\alpha \mathrm{B}$-crystallin, both in rats, and in a myocardial cell line, following exposure to high temperature.

\section{Materials and methods}

Animals and experimental design. All experiments were performed in accordance with the guidelines of the Animal Ethics Committee of Jiangsu province (China) and were approved by the Institutional Animal Care and Use Committee of Nanjing Agricultural University (Nanjing, China). Sixty-day-old Sprague Dawley rats $(n=60)$ were obtained from Qing Long Shan Company (Nanjing (China) and housed at room temperature $\left(25^{\circ} \mathrm{C}\right)$ for 5 days. The rats were then randomly divided into six groups $(n=10)$ : Five heat-stress exposure groups (for 20, 40, 60, 80 and $100 \mathrm{~min}$, respectively) and a control group. All animals were given ad libitum access to water and were fed the same feed during the experiments. A controlled-climate chamber (New Jiangnan Instrument Co., Ltd., Ningbo, Zhejiang) was pre-heated to $42^{\circ} \mathrm{C}$ with circulating fresh air, and the relative humidity was kept between $55-65 \%$. The control rats were maintained at room temperature. The mental state and activities of the control and heat-stressed rats were observed and recorded. Following each heat-stress period, the rats were sacrificed within $3 \mathrm{~min}$. Blood samples were then collected, and the hearts were divided into two sections: The ventriculus sinister, which was fixed in $4 \%$ paraformaldehyde for pathologic observation, and the ventriculus dexter, which was stored in liquid nitrogen until further experimentation.

Cell subculture and preparation. The $\mathrm{H} 9 \mathrm{c} 2$ myocardial cells (American Type Culture Collection, Manassas, VA, USA) were subcultured in Dulbecco's modified Eagle's medium supplemented with $10 \%$ fetal calf serum (Gibco Life Technologies, Carlsbad, CA, USA), and incubated at $37^{\circ} \mathrm{C}$ in an atmosphere containing $5 \% \mathrm{CO}_{2}$, until the fusion rate of the $\mathrm{H} 9 \mathrm{c} 2$ cells was $>90 \%$. The cells were then divided into six groups: A control group (0 min), and five groups exposed to heat stress for 20, 40, 60,80 and $100 \mathrm{~min}$. For prompt heat exposure, the temperature in the incubator was raised from 37 to $42^{\circ} \mathrm{C}$ in a humidified atmosphere containing $5 \% \mathrm{CO}_{2}$.

Western blot analysis. For protein extraction, all experimental rats were humanely sacrificed by decapitation. A total of $\sim 100 \mu \mathrm{g}$ heart tissue was collected and homogenized in $1 \mathrm{ml}$ phosphate-buffered saline (PBS) using a 623003 Fluko ${ }^{\circledR}$ Super Fine Homogenizer (Fluko Equipment Shanghai Co. Ltd., Shanghai, China) and centrifuged at 2,000 x g. The cell pellets were resuspended in $200 \mu \mathrm{l}$ ice-cold radioimmunoprecipitation assay lysis buffer containing $50 \mathrm{mM}$ Tris, (pH 7.4), $150 \mathrm{mM}$ $\mathrm{NaCl}, 1 \% \mathrm{NP}-40,0.5 \%$ sodium deoxycholate, $0.1 \% \mathrm{SDS}$, and $1 \mathrm{ml}$ phenylmethylsulfonyl fluoride WB-0071 (Beijing Ding Guo Chang Sheng Biotechnology Co. Ltd., Beijing, China). The homogenates were then centrifuged at $14,000 \mathrm{x} \mathrm{g}$ for 5 min at $4^{\circ} \mathrm{C}$, and the obtained supernatants were used as total protein extracts. Following 0, 20, 40, 60, 80 and $100 \mathrm{~min}$ of heat stress treatment in an incubator at $42^{\circ} \mathrm{C}, \mathrm{H} 9 \mathrm{c} 2$ cells were washed twice with PBS and lysed in M-PERH mammalian protein extraction reagent (28501; Thermo Fisher Scientific, Inc., Waltham, MA, USA) supplemented with Halt ${ }^{\mathrm{TM}}$ protease inhibitor cocktail according to the manufacturer's instructions (Thermo Fisher Scientific, Inc.). The cell homogenates were then centrifuged at $14,000 \mathrm{x}$ g for $5 \mathrm{~min}$ at $4^{\circ} \mathrm{C}$ and the supernatants were used as total protein extracts. All protein concentrations were measured using a Micro-Bicinchoninic Acid $^{\mathrm{TM}}$ Protein Assay kit (Thermo Fisher Scientific, Inc.). A total of $20 \mu \mathrm{g} \mathrm{H} 9 \mathrm{c} 2$ protein and heart sample protein $(80 \mu \mathrm{g})$ were loaded onto a $13 \%$ acrylamide gel with a $4 \%$ stacking acrylamide gel. Migration was performed using a buffer containing $25 \mathrm{mM}$ Tris, $\mathrm{pH}$ 7.6, 0.1\% SDS, and 0.2 mg lysine. The proteins in the gels were transferred onto a polyvinylidene difluoride membrane (Bio-Rad Laboratories, Inc., Hercules, CA, USA). The membranes were then blocked for $1 \mathrm{~h}$ at room temperature in Tris-buffered saline with Tween 20 (TBST; Sigma-Aldrich, St. Louis, MO, USA) containing 5\% milk powder, and incubated overnight at room temperature with $\alpha \mathrm{B}$-crystallin mouse immunoglobulin $\mathrm{G}$ monoclonal primary antibody (cat. no. ADI-SPA-222-F) and GAPDH mouse IgG monoclonal primary antibody (cat. no. ADI-CSA-335-E) (Enzo Life Sciences, Inc., Farmingdale, NY, USA). The blots were washed three times for $5 \mathrm{~min}$ in TBST and 5\% skim milk powder containing goat anti-mouse antibody (cat. no. SN133; Sunshine Biotechnology Nanjing Co. Ltd., Nanjing, China) at room temperature for $1 \mathrm{~h}$. Following three 5 min washes with TBST, the bands were revealed using diaminobenzidine (Sigma-Aldrich) in a $30 \mathrm{ml}$ buffer containing $60 \mathrm{mM}$ Tris, $\mathrm{pH} 6.8,0.2 \%$ hydrogen peroxide, and $200 \mathrm{ml} 0.8 \% \mathrm{NiCI}_{2}$. Following staining, the membranes were washed in distilled water and dried at $37^{\circ} \mathrm{C}$ in an oven. The bands on the developed film were quantified with Quantity One software, version 4.6.2 (Bio-Rad Laboratories, Inc.). The density of each band was normalized to that of the GADPH protein.

\section{Detection of $\alpha B$-crystallin and hsp27 mRNA by fluorescence reverse transcription-quantitative polymerase chain reaction $(R T-q P C R)$ in vivo and in vitro}

Isolation of total RNA and reverse transcription. Total RNA was extracted from the cultured $\mathrm{H} 9 \mathrm{c} 2$ cells using RNAiso Plus reagent (Takara Biotechnology Co., Ltd., Dalian, China), according to the manufacturer's instructions. Briefly, after H9c2 myocytes were heat-stressed at $42^{\circ} \mathrm{C}$ for various time periods, $1 \mathrm{ml}$ RNAiso Plus reagent was added to $10 \mathrm{~mm}^{2}$ cell culture plates. For the rat tissue samples, $100 \mathrm{mg}$ heart tissue was homogenized with the 623003 Fluko ${ }^{\circledR}$ Super Fine Homogenizer and $1 \mathrm{ml}$ RNA extraction buffer (TRIzol; 
Takara Biotechnology, Co., Ltd.) was added, according to the manufacturer's instructions. RNA concentration was determined using a M200PRO spectrophotometer (Tecan Austria GmbH, Grödig, Austria). RNA samples were synthesized into cDNA using PrimeScript Reverse Transcriptase Master Mix Perfect Real Time (cat. no. DRR036A; Takara Biotechnology Co., Ltd.), according to the manufacturer's instructions, and stored at $-80^{\circ} \mathrm{C}$ for further analysis.

Design of PCR primers. Primer sets were specifically designed to anneal to each target mRNA. The sequences for Hsp27, $\alpha$ B-crystallin and GAPDH mRNA were obtained from the National Center for Biotechnology Information Genbank (accession nos. NC_005111.4, NC_005107.4 and NC_005103.4, respectively). The primers were designed using the Primer Premier 5.0 software (Premier Biosoft, Palo Alto, CA, USA) for conventional and RT-qPCR amplification. The primer sequences for the genes were as follows: Hsp27, forward 5'-CGTGGTGGAGATCACTGGCAAGC-3', and reverse 5'-CGGGCCTCGAAAGTGACCGG-3'; and $\alpha$ B-crystallin, forward 5'-CACGAAGAGCGCCAGGACGA-3', and reverse 5'-CGTCGGCTGGGATCCGGTACT-3'; GAPDH, forward 5'-GGCTCTCTGCTCCTCCCTGTTCTAG-3' and reverse 5'-GGCTCTCTGCTCCTCCCTGTTCTAG-3'. The expected sizes of the Hsp27 and $\alpha \mathrm{B}$-crystallin PCR products were 216 and $153 \mathrm{bp}$, respectively. Primers were obtained from Invitrogen Life Technologies (Shanghai, China).

$R T$-qPCR. Using the iQ5 Real-Time PCR Detection system thermocycler (Bio-Rad Laboratories, Inc.), each cDNA sample ( $2 \mu 1,10 \mathrm{X}$ dilution) was suspended in $2 \mathrm{X} \mathrm{iQ}^{\mathrm{TM}} \mathrm{SUPER}^{\circledR}$ Green Supermix (Bio-Rad Laboratories, Inc.) with $0.6 \mu 1$ of both sense and antisense primers, and double-distilled water to a total volume of $20 \mu \mathrm{l}$. The PCR cycling conditions were as follows: Enzyme activation was carried out at $95^{\circ} \mathrm{C}$ for $3 \mathrm{~min}$ followed by 40 cycles of denaturation at $95^{\circ} \mathrm{C}$ for $20 \mathrm{sec}$, annealing at $60^{\circ} \mathrm{C}$ for $30 \mathrm{sec}$ and elongation at $72^{\circ} \mathrm{C}$ for $30 \mathrm{sec}$.

For each run, a negative control tube without cDNA was analyzed alongside the experimental groups. A 4-fold dilution series of the template was used in the PCR amplification reactions. The data were analyzed using Bio-Rad iQ5 software (Bio-Rad Laboratories, Inc.) and the $\alpha \mathrm{B}$-crystallin mRNA levels were normalized using the following formula: Relative quantity of $\alpha \mathrm{B}$-crystallin/hsp27 mRNA $=2^{-\Delta \Delta \mathrm{Ct}}$ $\Delta \Delta \mathrm{Ct}=\left[\left(\mathrm{Ct}_{\alpha \mathrm{B} \text {-crystallin/hsp27 }} \mathrm{mRNA}-\mathrm{Ct}_{\mathrm{GAPDH}} \mathrm{mRNA}\right)\right.$ control group - $\left(\mathrm{Ct}_{\mathrm{aB} \text {-crystallin/hsp27 }} \mathrm{mRNA}-\mathrm{Ct}_{\mathrm{GAPDH}} \mathrm{mRNA}\right)$ test group].

Analysis of the association between Hsp27 and $\alpha B$-crystallin. To analyze the association between Hsp27 and $\alpha \mathrm{B}$-crystallin, the STRING 9.1 database (http://string-db. rg/) was used, which aims to provide a global perspective for as many organisms as possible. In the STRING database, known and predicted associations are scored and integrated, resulting in comprehensive protein networks covering $>1,100$ organisms. This software extends the automated mining of scientific texts for interaction information, and also includes full-text articles (21).

Statistical analysis. Statistical differences between the heat-stressed groups and the control group were analyzed by one-way analysis of variance followed by a least significant difference multiple comparison test, using the SPSS 20.0 for Windows (IBM SPSS, Armonk, NY, USA). The results were expressed as the mean \pm standard deviation of at least three independent experiments. All experiments were performed in triplicate. $\mathrm{P}<0.05$ was considered to indicate a statistically significant difference.

\section{Results}

Protein expression levels of Hsp27 and $\alpha B$-crystallin in vivo in response to heat stress. The protein expression levels of Hsp27 and $\alpha \mathrm{B}$-crystallin were measured in vivo in response to various durations of exposure to heat shock, and normalized to GAPDH (Fig. 1). In the heat-stressed rat heart, $\alpha \mathrm{B}$-crystallin decreased significantly $(\mathrm{P}<0.01)$ after $20 \mathrm{~min}$ exposure to heat, but increased by almost 3 -fold after $40 \mathrm{~min}(\mathrm{P}<0.01)$, and decreased after 60,80 and $100 \mathrm{~min}(\mathrm{P}<0.01)$. The protein expression levels of Hsp27 decreased significantly $(\mathrm{P}<0.01)$ after all durations of exposure to heat stress; however, after $40 \mathrm{~min}$, the expression levels of Hsp27 were higher, as compared with after $20 \mathrm{~min}$.

Protein expression levels of Hsp27 and $\alpha B$-crystallin in vitro in response to heat stress. The protein expression levels of Hsp27 and $\alpha \mathrm{B}$-crystallin were measured in vitro in response to various durations of exposure to heat shock, and normalized to GAPDH (Fig. 2). The expression levels of $\alpha \mathrm{B}$-crystallin decreased significantly $(\mathrm{P}<0.01)$ after 40 and $60 \mathrm{~min}$ of heat stress, as compared with the control group, but increased after 80 and $100 \mathrm{~min}$ of exposure to heat stress $(\mathrm{P}<0.01)$. However, no statistically significant difference in the expression levels of $\alpha \mathrm{B}$-crystallin was observed between the 80 and $100 \mathrm{~min}$ groups. The expression levels of Hsp27 decreased after $40 \mathrm{~min}$ of heat exposure $(\mathrm{P}<0.01)$, but after 60,80 and 100 min the expression levels increased, as compared with the control group.

$m R N A$ expression levels of Hsp27 and $\alpha B$-crystallin in vivo in response to heat stress. The mRNA expression levels of Hsp27 and $\alpha \mathrm{B}$-crystallin in response to heat shock exposure in vivo, normalized to the GAPDH gene, are displayed in Fig 3. The RT-qPCR results demonstrated that compared with the control group, the mRNA expression levels of $\alpha \mathrm{B}$-crystallin and Hsp27 were significantly increased after 20, 40, 60, 80 and $100 \mathrm{~min}$ of heat stress in the rat heart $(\mathrm{P}<0.01)$.

mRNA expression levels of Hsp27 and $\alpha B$-crystallin in vitro in response to heat stress. The mRNA expression levels of hsp27 and $\alpha \mathrm{B}$-crystallin in response to heat shock exposure in vitro, normalized to the GAPDH gene, are displayed in Fig. 4. The mRNA expression levels of $\alpha \mathrm{B}$-crystallin were significantly reduced $(\mathrm{P}<0.01)$ following 20,40 and 80 min heat shock exposure, and those of Hsp27 were significantly increased $(\mathrm{P}<0.01)$ following 20 and $40 \mathrm{~min}$ heat shock exposure. However, following $60 \mathrm{~min}$ of heat shock exposure, the levels of Hsp27 and $\alpha \mathrm{B}$-crystallin exhibited similar trends.

The association between Hsp27 and $\alpha B$-crystallin. These preliminary results suggest that the protein and mRNA expression levels of Hsp27 and $\alpha \mathrm{B}$-crystallin exhibit a similar trend in heat-stressed myocardial cells in vivo and in vitro, respectively. According to the rat database in STRING, $\alpha \mathrm{B}$-crystallin is able to bind Hsp27 in rat cells (Fig. 5A). In 


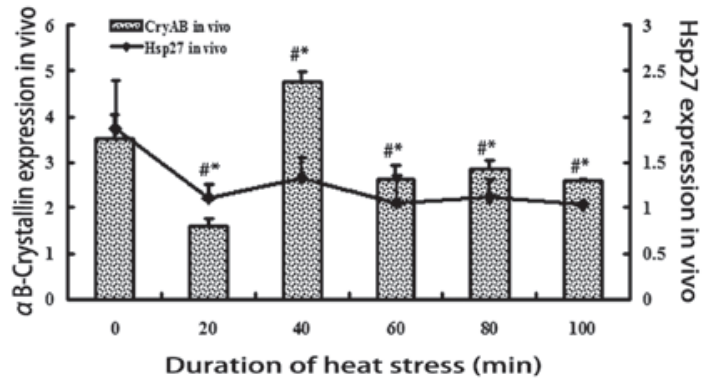

Figure 1. The protein expression levels of heat shock protein 27 (Hsp27) and $\alpha \mathrm{B}$-crystallin (cryAB) in heat-stressed myocardial cells in vivo. ${ }^{\#} \mathrm{P}<0.01$ (CryAB), and ${ }^{*} \mathrm{P}<0.01$ (Hsp27).

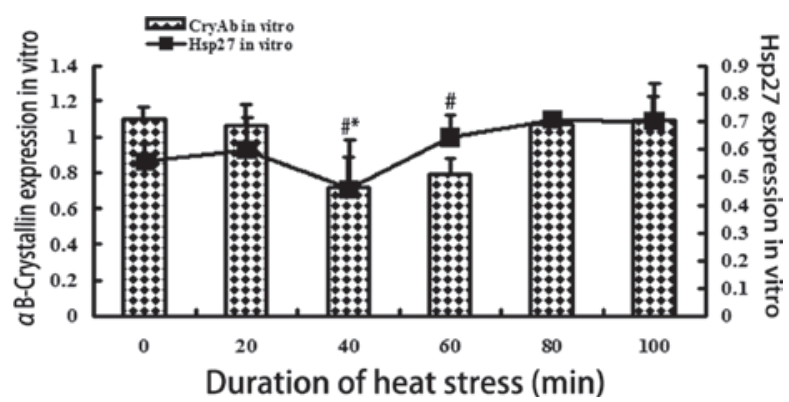

Figure 2. The protein expression levels of heat shock protein 27 (Hsp27) and $\alpha \mathrm{B}$-crystallin (cryAB) in heat-stressed $\mathrm{H} 9 \mathrm{c} 2$ myocardial cells in vitro. ${ }^{\#} \mathrm{P}<0.01$ (CryAB), and ${ }^{*} \mathrm{P}<0.01$ (Hsp27).

the evidence view in STRING (Fig. 5B), the different colors represent various sources of evidence from the database and experiments, and confirmed the co-expression of $\alpha \mathrm{B}$-crystallin and Hsp27. Compared with other proteins that are associated with $\alpha \mathrm{B}$-crystallin, such as Hspb2, Hsp27 has the highest co-expression score with $\alpha \mathrm{B}$-crystallin (Fig. 5C). The co-expression view (Fig. 5D) indicated that $\alpha \mathrm{B}$-crystallin and Hsp27 are co-expressed in rats, but not in other species, such as Homo sapiens. In the present study, both the protein and mRNA expression levels of Hsp27 and $\alpha \mathrm{B}$-crystallin exhibited similar trends in response to heat shock in vivo and in vitro, respectively, thus indicating that they may be co-expressed.

\section{Discussion}

Heat stress causes extensive cytoskeletal and mitochondrial damage, as well as uncoupling of oxidative phosphorylation. Hsps are thought to limit injury and accelerate recovery by refolding disrupted proteins and preventing deleterious peptide interactions $(17,22)$. sHsps are a widespread and diverse class of proteins. Of the major Hsps, Hsp27 and $\alpha \mathrm{B}$-crystallin have recently been identified as molecular chaperones (9). Stressors that transiently induce Hsp27 and $\alpha \mathrm{B}$-crystallin include heat shock, anticancer drugs, radiation, and oxidative stress. As compared with other Hsps, Hsp27 and $\alpha \mathrm{B}$-crystallin bind to numerous non-native proteins via an oligomeric complex, and thus represent the most efficient chaperones in terms of quantity of substrate binding $(14,23)$. In the present study, the mRNA expression levels of $\alpha \mathrm{B}$-crystallin were significantly reduced $(\mathrm{P}<0.01)$ following 20,40 and 80 min heat shock exposure, and those of Hsp27 were significantly increased

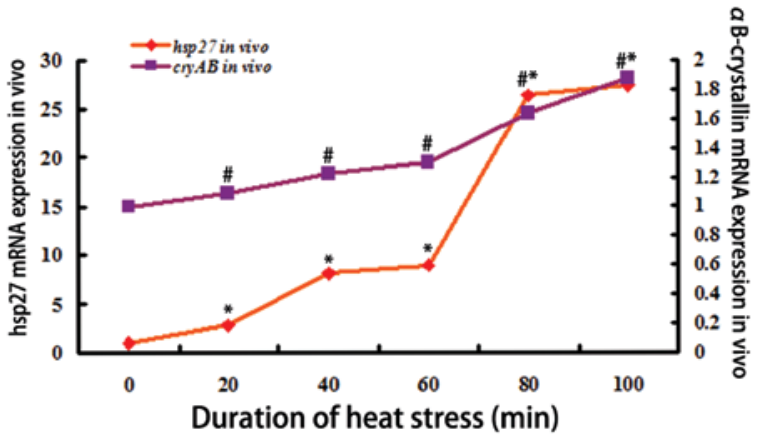

Figure 3. The mRNA expression levels of heat shock protein 27 (Hsp27) and $\alpha \mathrm{B}$-crystallin (cryAB) in heat-stressed myocardial cells in vivo. ${ }^{\#} \mathrm{P}<0.01$ (CryAB), and ${ }^{*} \mathrm{P}<0.01$ (Hsp27)

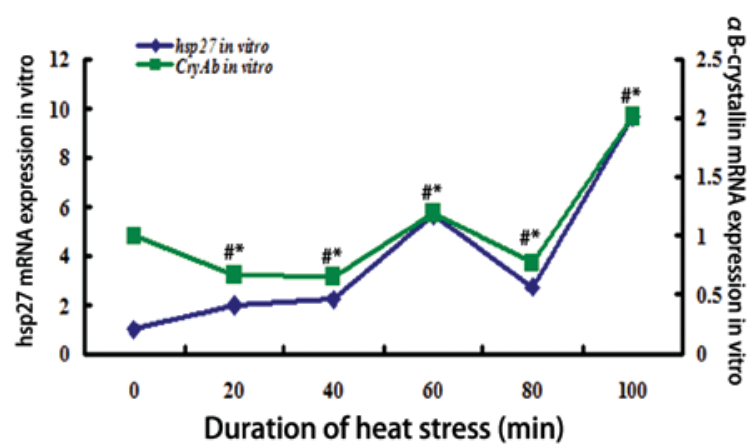

Figure 4.The mRNA expression levels of heat shock protein 27 (Hsp27) and $\alpha \mathrm{B}$-crystallin (cryAB) in heat-stressed $\mathrm{H} 9 \mathrm{c} 2$ myocardial cells in vitro. ${ }^{\#} \mathrm{P}<0.01$ (CryAB), and ${ }^{*} \mathrm{P}<0.01$ (Hsp27).

$(\mathrm{P}<0.01)$ following 20 and 40 min heat shock exposure. However, following $60 \mathrm{~min}$ of heat shock exposure, the levels of Hsp27 and $\alpha \mathrm{B}$-crystallin exhibited similar trends. The protein expression levels of Hsp27 decreased after 40 min, as compared with the other groups, whereas $\alpha \mathrm{B}$-crystallin decreased only after 40 and $60 \mathrm{~min}$ of heat exposure in vitro. After $60 \mathrm{~min}$, both sHsps exhibited an increase in expression levels. The protein expression trends of both sHsps were not concordant with their mRNA expression levels from the initiation of heat stress in vitro, however at 100 min sharply increased to mRNA levels consistant with the levels of protein expression. However, in heat-stressed rat heart in vivo, both the mRNA expression levels of Hsp27 and $\alpha \mathrm{B}$-crystallin significantly increased after all durations of heat exposure. A previous study suggested that the expression levels of Hsp27 and $\alpha \mathrm{B}$-crystallin may be regulated at the transcriptional level (24). However, in rat hearts in vivo, the protein expression levels of Hsp27 and $\alpha \mathrm{B}$-crystallin decreased, except for $\alpha \mathrm{B}$-crystallin after $40 \mathrm{~min}$ of heat exposure. Both sHsps exhibited decreased expression level trends after $100 \mathrm{~min}$ of heat stress. A previous study demonstrated that Hsp27 and $\alpha \mathrm{B}$-crystallin mRNA is overexpressed in the heart and other smooth muscles following heat stress, but the expression of their corresponding proteins does not follow the same trend (25). The present study investigated the mRNA and protein expression levels of Hsp27 and $\alpha \mathrm{B}$-crystallin in response to heat stress. Hsp27 and $\alpha \mathrm{B}$-crystallin may modulate interactions between cellular factors by forming 
A

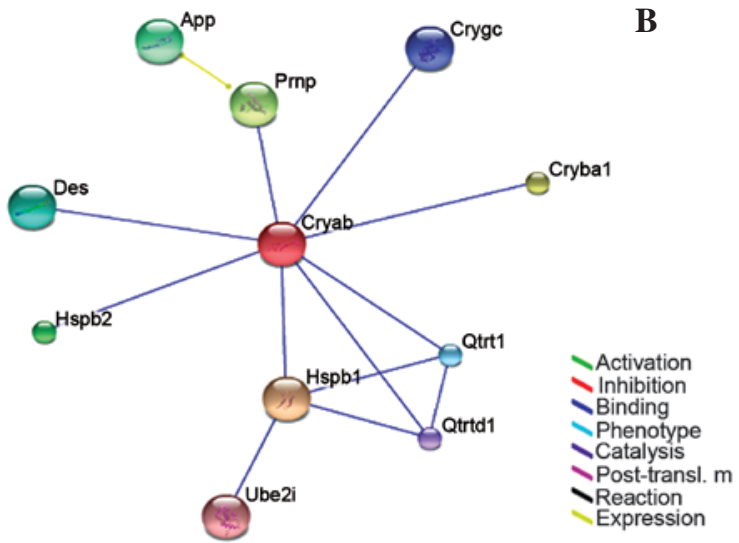

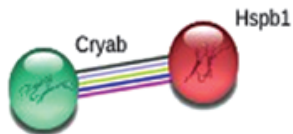

$\checkmark$ Neighborhood $\checkmark$ Co-occurence $\checkmark$ Co-expression Experiments - Databases THomology]

C

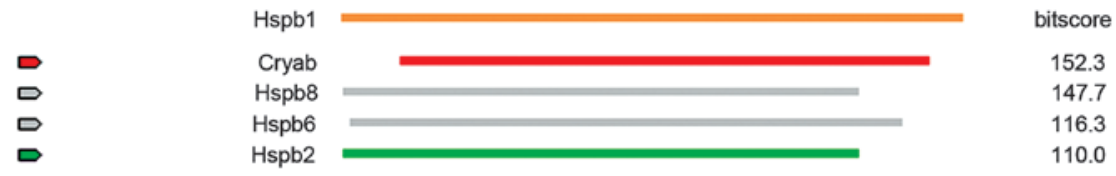

D

- Co-expression -

association score

0.0

1.0

... from co-expression in

Rattus norvegicus:

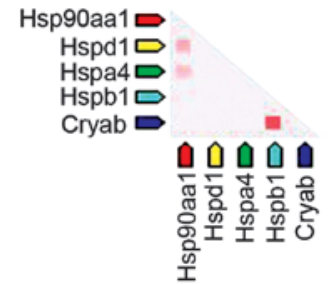

... from co-expression in other species (transferred):
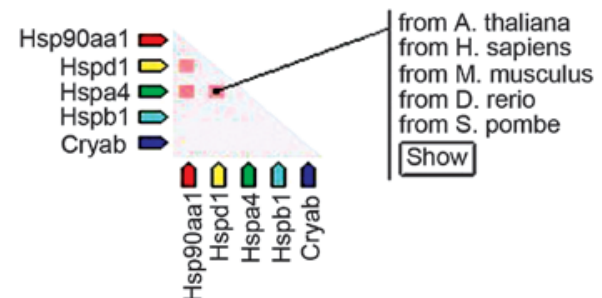

Figure 5. The association between heat shock protein (Hsp)27 and $\alpha$ B-crystallin in rat myocardial cells, as determined by STRING 9.1: CryAB, $\alpha$ B-crystallin; HspB1, Hsp27. (A) The various proteins that are associated with $\alpha$ B-crystallin (Hsp27 binds to $\alpha B$-crystallin, blue line). (B) The association between Hsp27 and $\alpha \mathrm{B}$-crystallin has been confirmed by previous studies: Various colors indicate various sources of evidence. (C) The co-expression score between Hsp27 and $\alpha \mathrm{B}$-crystallin was calculated, which is higher than that of all the other proteins. (D) Hsp27 and $\alpha \mathrm{B}$-crystallin are not co-expressed in all species (including Homo sapiens). App, amyloid beta (A4) precursor protein; Pmp, peripheral myelin protein; Cry, crystallin; Des, desmin.

small or large oligomers, undergoing phosphorylation, and inducing cell-cell contact in vivo $(7,22,24)$. A previous study confirmed that Hsp27 and $\alpha \mathrm{B}$-crystallin exhibited a phosphorylation response in the atrial myocardium of patients undergoing valve repair (22). However, the specific mechanism underlying this phosphorylation response remains to be investigated.

In response to stressful conditions, $\alpha \mathrm{B}$-crystallin is able to bind to Hsp27, relocalize to the cytoskeleton, and binds to microtubules via microtubule-associated proteins, which may protect the cells from damaged intracellular proteins by sequestering these proteins on the cytoskeleton $(15,26)$. The present study demonstrated that the expression levels of Hsp27 and $\alpha \mathrm{B}$-crystallin markedly differ in the rat heart in vivo, as compared with the $\mathrm{H} 9 \mathrm{c} 2$ cells in vitro. In the whole rat body, there may be numerous factors that affect the heat-stressed heart. The protein expression levels of Hsps in cardiomyocytes may be regulated by hormones. Thyroid hormones may be involved in the regulation of Hsp27 expression in the rat myocardium (27). However, in the $\mathrm{H} 9 \mathrm{c} 2$ cell line, after $60 \mathrm{~min}$ exposure to heat stress, the protein expression levels of both sHsps increased to reach a baseline level, which was different from their expression trends in vivo. The comparative analysis of the present study suggests that the mechanism underlying this protection is not the same between the individual cell and the whole body. During the experiments, the mortality rate of heat-stressed rats was $100 \%$ after $120 \mathrm{~min}$. The low protein expression levels of both Hsps after $80 \mathrm{~min}$ indicated that the inherent expression levels of Hsp27 and $\alpha \mathrm{B}$-crystallin may not be enough to resist acute heat stress (28). A previous study demonstrated that overexpression of Hsp27 offers protection via an anti-apoptotic mechanism (15). However, these observations still require confirmation, and pre-induction of sHsps prior to heat stress may be an effective way to reduce the mortality rate.

In the present study, Hsp27 and $\alpha \mathrm{B}$-crystallin were activated by acute heat stress at both the mRNA and protein level in vivo and in vitro. These results were concordant with those of previous studies that demonstrated that Hsp27 and $\alpha \mathrm{B}$-crystallin have similar roles when subjected to various stressors $(29,30)$. Hsp27 and $\alpha \mathrm{B}$-crystallin are characterized 
by a conserved $\mathrm{C}$-terminal region, termed the $\alpha \mathrm{B}$-crystallin domain, a variable $\mathrm{N}$-terminal sequence, and in most cases a short and variable C-terminal tail (16). The results of the present study suggested that the protein and mRNA expression levels of both Hsp27 and $\alpha \mathrm{B}$-crystallin exhibit similar trends in the $\mathrm{H} 9 \mathrm{c} 2$ rat cell line. Furthermore, as confirmed by STRING, these results support the evidence that $\alpha \mathrm{B}$-crystallin is able to bind to Hsp27 in rat cells (Fig. 5B). The co-expression score between $\alpha \mathrm{B}$-crystallin and Hsp27 was the highest in rats, but did not occur in all the species analyzed (including Homo sapiens). A previous study demonstrated that Hsp27 and $\alpha \mathrm{B}$-crystallin proteins often accumulate as inclusion bodies in numerous protein conformation diseases, and have a similar role to molecular chaperones (19). Investigating the specific mechanism underlying the co-expression of Hsp27 and $\alpha \mathrm{B}$-crystallin will provide the basis for our future experiments.

In conclusion, Hsp27 and $\alpha \mathrm{B}$-crystallin are activated by acute heat stress both at the mRNA and protein level in vivo and in vitro. However, the expression levels of Hsp27 and $\alpha \mathrm{B}$-crystallin differed between the whole body system and the cell line when subjected to heat stress. When co-expressed, Hsp27 and $\alpha \mathrm{B}$-crystallin may have roles in rat myocardial cells in vivo and in vitro.

\section{Acknowledgements}

The current study was supported by grants from the National Key Basic Research Program of China (973 Program; grant no. 2014CB138502), the National Natural Science Foundation of China (grant no. 31372403), the National Department Public Benefit Research Foundation (Agriculture) (grant no. 201003060-11), the Priority Academic Program Development of Jiangsu Higher Education Institutions, Graduate Research and Innovation Projects in Jiangsu Province and the Sino-German Agricultural Cooperation Project of the Federal Ministry of Food, Agriculture and Consumer Production, Berlin, Germany.

\section{References}

1. Rohde MC, Corydon TJ, Hansen J, Pedersen CB, Schmidt SP, Gregersen N and Banner J: Heat stress and sudden infant death syndrome - stress gene expression after exposure to moderate heat stress. Forensic Sci Int 232: 16-24, 2013.

2. Feder ME and Hofmann GE: Heat-shock proteins, molecular chaperones, and the stress response: Evolutionary and ecological physiology. Annu Rev Physiol 61: 243-282, 1999.

3. Herbst J, Gilbert JD and Byard RW: Urinary incontinence, hyperthermia, and sudden death. J Forensic Sci 56: 1062-1063, 2011.

4. Zhu Y, Lu X, Wu D, Cai S, Li S and Teng X: The effect of manganese-induced cytotoxicity on mRNA expressions of HSP27, HSP40, HSP60, HSP70 and HSP90 in chicken spleen lymphocytes in vitro. Biol Trace Elem Res 156: 144-152, 2013.

5. Martin J, Horwich AL and Hartl FU: Prevention of protein denaturation under heat stress by the chaperonin Hsp60. Science 258: 995-998, 1992.

6. Bagatell R, Paine-Murrieta GD, Taylor CW, Pulcini EJ, Akinaga S, Benjamin IJ and Whitesell L: Induction of a heat shock factor 1-dependent stress response alters the cytotoxic activity of hsp90-binding agents. Clin Cancer Res 6: 3312-3318, 2000.

7. Garrido C, Paul C, Seigneuric R and Kampinga HH: The small heat shock proteins family: The long forgotten chaperones. Int J Biochem Cell Biol 44: 1588-1592, 2012.

8. Singh IS and Hasday JD: Fever, hyperthermia and the heat shock response. Int J Hyperthermia 29: 423-435, 2013.
9. Adhikari AS, Sridhar Rao K, Rangaraj N, Parnaik VK and Mohan Rao Ch: Heat stress-induced localization of small heat shock proteins in mouse myoblasts: Intranuclear lamin A/C speckles as target for alphaB-crystallin and Hsp25. Exp Cell Res 299: 393-403, 2004.

10. Ananthan J, Goldberg AL and Voellmy R: Abnormal proteins serve as eukaryotic stress signals and trigger the activation of heat shock genes. Science 232: 522-524, 1986.

11. Beere HM: "The stress of dying": The role of heat shock proteins in the regulation of apoptosis. J Cell Sci 117: 2641-2651, 2004.

12. Arya R, Mallik M and Lakhotia SC: Heat shock genes - integrating cell survival and death. J Biosci 32: 595-610, 2007.

13. Knowlton AA, Brecher P and Apstein CS: Rapid expression of heat shock protein in the rabbit after brief cardiac ischemia. J Clin Invest 87: 139-147, 1991.

14. Acunzo J, Katsogiannou M and Rocchi P: Small heat shock proteins HSP27 (HspB1), $\alpha$ B-crystallin (HspB5) and HSP22 (HspB8) as regulators of cell death. Int J Biochem Cell Biol 44: 1622-1631, 2012.

15. Concannon CG, Gorman AM and Samali A: On the role of Hsp27 in regulating apoptosis. Apoptosis 8: 61-70, 2003.

16. Kappé G, Franck E, Verschuure P, Boelens WC, Leunissen JA and de Jong WW: The human genome encodes 10 alpha-crystallin-related small heat shock proteins: HspB1-10. Cell Stress Chaperones 8: 53-61, 2003.

17. Lanneau D, Wettstein G, Bonniaud P and Garrido C: Heat shock proteins: Cell protection through protein triage. ScientificWorldJournal 10: 1543-1552, 2010.

18. Wettstein G, Bellaye PS, Micheau O and Bonniaud P: Small heat shock proteins and the cytoskeleton: An essential interplay for cell integrity? Int J Biochem Cell Biol 44: 1680-1686, 2012.

19. Zoubeidi A and Gleave M: Small heat shock proteins in cancer therapy and prognosis. Int J Biochem Cell Biol 44: 1646-1656, 2012.

20. Moseley PL: Heat shock proteins and heat adaptation of the whole organism. J Appl Physiol (1985) 83: 1413-1417, 1997.

21. Franceschini A, Szklarczyk D, Frankild S, Kuhn M, Simonovic M, Roth A, Lin J, Minguez P, Bork P, von Mering C and Jensen LJ: STRING v9.1: Protein-protein interaction networks, with increased coverage and integration. Nucleic Acids Res 41: D808-D815, 2013.

22. Clements RT, Feng J, Cordeiro B, Bianchi C and Sellke FW: p38-MAPK-dependent small HSP27 and $\alpha \mathrm{B}$-crystallin phosphorylation in regulation of myocardial function following cardioplegic arrest. Am J Physiol Heart Circ Physiol 300: H1669-H1677, 2011.

23. Baler R, Dahl G and Voellmy R: Activation of human heat shock genes is accompanied by oligomerization, modification, and rapid translocation of heat shock transcription factor HSF1. Mol Cell Biol 13: 2486-2496, 1993.

24. Parcellier A, Schmitt E, Brunet M, Hammann A, Solary E and Garrido C: Small heat shock proteins HSP27 and alphaB-crystallin: Cytoprotective and oncogenic functions. Antioxid Redox Signal 7: 404-413, 2005.

25. Sugiyama Y, Suzuki A, Kishikawa M, Akutsu R, Hirose T, Waye MM, Tsui SK, Yoshida S and Ohno S: Muscle develops a specific form of small heat shock protein complex composed of MKBP/HSPB2 and HSPB3 during myogenic differentiation. J Biol Chem 275: 1095-1104, 2000.

26. Fostinis Y, Theodoropoulos PA, Gravanis A and Stournaras C: Heat shock protein HSP90 and its association with the cytoskeleton: A morphological study. Biochem Cell Biol 70: 779-786, 1992.

27. Knowlton AA and Sun L: Heat-shock factor-1, steroid hormones, and regulation of heat-shock protein expression in the heart. Am J Physiol Heart Circ Physiol 280: H455-H464, 2001.

28. Tang S, Buriro R, Liu Z, Zhang M, Ali I, Adam A, Hartung J and Bao E: Localization and expression of Hsp27 and $\alpha \mathrm{B}$-crystallin in rat primary myocardial cells during heat stress in vitro. PloS One 8: e69066, 2013.

29. Ito H, Kamei K, Iwamoto I, Inaguma Y, Tsuzuki M, Kishikawa M, Shimada A, Hosokawa M and Kato K: Hsp27 suppresses the formation of inclusion bodies induced by expression of R120G $\alpha$ B-crystallin, a cause of desmin-related myopathy. Cell Mol Life Sci 60: 1217-1223, 2003.

30. Chávez Zobel AT, Loranger A, Marceau N, Thériault JR, Lambert $\mathrm{H}$ and Landry J: Distinct chaperone mechanisms can delay the formation of aggresomes by the myopathy-causing R120G alphaB-crystallin mutant. Hum Mol Genet 12: 1609-1620, 2003. 